\title{
Fabric Structural Parameters Effect on Seam Efficiency-Effect of Woven Fabric Structural Parameters on Seam Efficiency
}

\author{
Iftikhar $\mathrm{F}^{1 *}$, Hussain $\mathrm{T}^{1}$, Malik $\mathbf{M H}^{2}$, Ali $\mathbf{Z}^{1}$, Nazir $\mathbf{A}^{1}$, Riaz $\mathbf{S}^{1}$ and Malik $\mathbf{S}^{1}$
}

${ }^{1}$ Comfort Textile Research Group, National Textile University, Sheikhupura Road, Faisalabad, Pakistan

${ }^{2}$ Department of Textile and Design, University of Management and Technology, C-Il, Johar Town, Lahore, Pakistan

\begin{abstract}
This paper investigates the seam strength and efficiency along with, how fabric structural and sewing parameters as: weave design, weft density and seam type effect the strength and efficiency of seams. Six cotton fabrics having three weave designs and two weft densities were developed and sewn by five different seam sub-types. The lockstitch sewing machine was used. Strength of fabrics and seams were tested on Instron tensile machine. Assessments of all results were conducted with respect to weave design, weft density and seam sub-types separately by using a factorial design variance analysis. The study found that weave design significantly affect the seam strength and its efficiency in both directions. The direction of stitch is most important for seam efficiency. Moreover, the increasing trend was found towards seam strength and its efficiency by increasing the weft density. Each seam sub-type has its own strength values relative to each type of weave design and weft density. This research emphasizes only on cotton fabric with selected fabric structural parameters and seam sub-types. The presented conclusion is effective only this group of parameters and cannot be used inclusively. Thus far, the effect of different fabric structural parameters with seams has not been studied previously. This concern has been fulfilled in this research.
\end{abstract}

Keywords: Fabric structural parameters; Fabric strength; Seam strength; Seam efficiency

\section{Introduction}

Clothing is the conversion of a two dimensional fabric into a three dimensional product. Many variables have involved such as selection of a suitable sewing thread, type of seam, optimization of sewing parameters, ease of conversion of fabric to product and actual performance of a sewn fabric during the use of product [1,2]. Fabric quality alone does not fulfil the criteria for production of high quality products.

The relative importance of woven fabrics is significantly high not only in conventional textiles and clothing but their share in technical textile is also quite large due to their good strength, durability and stable structure as compared to knitted fabric. The sewing process is one of the critical processes in the determination of productivity and the quality of the finished product [3]. The prediction of fabric performance during sewing process provide the basis for maintaining consistency of sewing quality among different types of fabric, as well as maintaining the quality standard throughout the sewing process [4]. The basic performance properties of seam include strength, elasticity, durability, efficiency and security.

These seam performance properties are affected by the fabric characteristics, seam designs and seam processing variables $[5,6]$. The term seam efficiency refers to the capacity of material itself to carry a seam. It is the ratio of seam strength to the un-sewn strength of the fabric expressed as percentage of fabric strength [7]. The seam strength is mainly dependent on the sewing thread properties, fabric characteristics and the sewing conditions. The needle size, stitch density, operation type and the maintenance of sewing machine are all sewing conditions. Chattopadhyay described that the property of fabric tensile strength is defined by the strength of yarn used in construction and design of fabric weave. If the fabric structure does not distribute the load equally between yarns and allows stress to concentrate on certain yarns, the fabric strength will be reduced due to asymmetric distribution of stress.

Fabric and sewing thread is the basic raw material in apparel and home textile industry. However, fabric and sewing thread are not the only factors affecting the seam performance. Sewing conditions also affect the seam quality [8]. Much work has been done to explore sewing parameters such as seam type, stitch type, needle size, stitch density, thread compatibility which have a great impact on the seam quality $[9,10]$.

The effect of sewing thread on seam efficiency of woven fabric has been clearly established by many researchers. The selection of suitable sewing conditions is essential for achieving good seam efficiency [11]. The researchers have reported that the core spun thread gives higher seam efficiency as compared to the conventional sewing thread and that the use of silicon finish decreases the seam efficiency [12].

The tensile strength of the woven fabric not only depends on the strength of the constituent yarns, but also on the fabric geometry, warp and weft density, weave designs, yarn interlacement pattern, weaving conditions as well as fabric finishing treatments [13,7]. Lapere reveals that tensile strength of woven fabric is decreased by the application of the sewing operations, and the ultimate serviceability of a sewn article depends on the technical features of the fabric as well as the seam.

The parameters which affect the efficiency of a seam include fabric type, weight, seam type, stitch type, stitch density, thread tension and thread strength. Seams are formed by stitching two or more pieces of fabric together, but the basis of seam classification is the position of pieces relative to each other at the junction where they are sewn. There

*Corresponding author: Iftikhar F, Comfort Textile Research Group, Nationa Textile University, Sheikhupura road, Faisalabad (37610), Pakistan, Tel: 923326697746; E-mail: fam.ftkhr@gmail.com

Received April 28, 2018; Accepted May 03, 2018; Published May 12, 2018

Citation: Iftikhar F, Hussain T, Malik MH, Ali Z, Nazir A, et al. (2018) Fabric Structural Parameters Effect on Seam Efficiency-Effect of Woven Fabric Structural Parameters on Seam Efficiency. J Textile Sci Eng 8: 358. doi: 10.4172/21658064.1000358

Copyright: $\odot 2018$ Iftikhar F, et al. This is an open-access article distributed under the terms of the Creative Commons Attribution License, which permits unrestricted use, distribution, and reproduction in any medium, provided the original author and source are credited. 
are four classes of seams such as; superimposed seam, lapped seam, bound seam and flat seam [9].

Durability of clothing is most important which determines by strength of seam. Many studies have been carried upon the parameters which affect the seam efficiency of woven fabric but there is still a gap of reported research work regarding the effect of fabric structural parameters with seam sub-types on the seam efficiency together.

\section{Experimental}

\section{Materials}

Six cotton woven structures of different areal density are used to observe the seam efficiency of fabrics which are generally used as clothing. The cotton fabrics having three different weave structures $(1 / 1$ Plain, 2/1 twill \& 4/1 satin), two different weft density for each weave type and five different seam sub-types for each weave and weft density were selected for investigational study. The detailed specification of the fabric samples are listed in Table 1. For preparation of sewn samples, 2 -ply $100 \%$ cotton sewing thread linear density of 39 Tex was used. The samples were stitched with five different seam sub-types.

\section{Methods}

In this study, seam strength and efficiency of woven fabrics were explored by means of weave, weft density and seam sub-types.

Preparation of sewn samples: A lockstitch sewing machine (JUKI DDL-8300N) with a round needle No. 90/14 was used for sewing the fabric samples with two-ply cotton sewing thread. In generally, synthetic sewing thread is being used because of good mechanical strength, but in this research $100 \%$ cotton sewing thread has been used to observe its influence on seam. The sewing machine and needle were selected due to the commercial need of industry. Five different seam sub-types (SSa, SSb, SSc, LSa, and LSb) and the stitch type 301 were used for sewing the samples with a stitch density of 4 stitches $/ \mathrm{cm}$. The construction images of selected seams are shown in Table 2.

\begin{tabular}{|c|c|}
\hline S.no. & $\begin{array}{c}\text { Weave } \\
\text { Design }\end{array}$ \\
\hline 1 & Plain \\
\hline 2 & Twill \\
\hline 3 & Satin \\
\hline 4 & Plain \\
\hline 5 & Twill \\
\hline 6 & Satin \\
\hline
\end{tabular}

\begin{tabular}{|c|c|c|c|c|}
$\begin{array}{c}\text { Ends/ } \\
\text { cm }\end{array}$ & $\begin{array}{c}\text { Picks/ } \\
\text { cm }\end{array}$ & $\begin{array}{c}\text { Warp } \\
\text { Count(tex) }\end{array}$ & $\begin{array}{c}\text { Weft count } \\
\text { (tex) }\end{array}$ & $\begin{array}{c}\text { Areal density } \\
\text { (g/m20) }\end{array}$ \\
\hline 50 & 20 & 20 & 20 & 162 \\
\hline 50 & 50 & 20 & 20 & 163 \\
\hline 50 & 20 & 20 & 20 & 154 \\
\hline 50 & 24 & 20 & 20 & 171 \\
\hline 50 & 24 & 20 & 20 & 166 \\
\hline 50 & 24 & 20 & 20 & 164 \\
\hline
\end{tabular}

Table 1: Fabric specifications.

\begin{tabular}{|c|c|c|}
\hline S.no. & Seam Designs & Construction Images \\
\hline 1 & Ssa & \\
\hline 2 & SSb \\
\hline 3 & SSc \\
\hline 4 & Lsa \\
\hline 5 & LSb \\
\hline
\end{tabular}

Table 2: Seam designs used.
Fabric strength: The stitched and unstitched fabric samples were placed in the standard atmospheric testing conditions according to before testing. The 78 samples of fabric were prepared for strength test according to using constant rate of traverse Instron tensile strength tester [14]. A sample size of 4 inch $\times 6$ inch was used for testing the fabric strength in both fabric width and length direction.

Seam strength: The 300 sewn samples were prepared by using five different seam sub-types. The strength of sewn sample was tested according to using constant rate of traverse Instron tensile strength tester [15]. A sample size of 4 inch $\times 8$ inch was used for testing the seam strength in both the fabric width and length direction. The seam efficiency was calculated according to eqn. (1).

$$
\text { Seam Efficiency }=\frac{(\text { SeamStrength })}{(\text { FabricStrength })} \times 100
$$

\section{Results and Discussion}

Factorial design variance analysis technique was used to investigate the effect of selected parameters on the response variables. The applicability of analysis technique on each of three responses both in the perpendicular and cross directions of un-seamed and seamed fabric was done. In a general full factorial experiment, responses are measured for all factor levels at all combinations. Each experimental condition is called a "run" and each measure is called an observation. $\mathrm{P}$-value is determinant of significance of a factor or response, in analysis of variance table. P-value is compared with alpha-level; a commonly used alpha-level is 0.05 . If the p-value is less than or equal to alpha, it is concluded that the effect is significant.

\section{Effect of fabric structural parameters on fabric strength}

The fabric tensile strength is the projection of the yarn strength and fabric structure. Here, the following two input parameters such as weave designs i.e., plain, twill, satin and weft densities i.e., 20 and $24 \mathrm{picks} / \mathrm{cm}$ were chosen to investigate their effect on fabric tensile strength both in fabric warp and weft direction separately by applying factorial analysis. The analysed data is given in Table 3; which showed the effect of weave design was statistically significant in warp direction (p-value $=0.05)$ but not in the weft direction ( $p$-value=0.32). The effect of weft density was statistically significant on fabric strength in the weft direction ( $p$-value $=0.01$ ). However, the effect was not significant in the warp direction ( $\mathrm{p}$-value $=0.16$ ).

The factorial plots are used to analyse the effect of factors on the response. If the factor is significant then greater would be the slope of the line and stronger would be the effect. It can be observed from the main-effect plot given in Figure 1; that satin fabric exhibited the highest strength whereas the plain fabric gave the lowest tensile strength. That could be due to the lowest crimp in satin fabric because of the least number of yarn interlacement.

During the process of tensile failure, the crimp and its interchange on constituent yarn has a reasonable impact on the tensile strength of fabric. It had been established in literature that higher crimp of fabric resulted into lower tensile modulus, higher elongation and lower breaking tensile strength [16]. The crimp also had great effect on fibre volume fraction, fabric thickness and fabric mechanical properties. Higher the crimp value would be increased the crimp angle which ultimately caused the jamming effect for the propagation of strength through the fabric, so the fabric strength decreased [17].

It is evident from Figure 2; that fabric strength increased both in warp and weft direction by increasing the number of picks in weft 

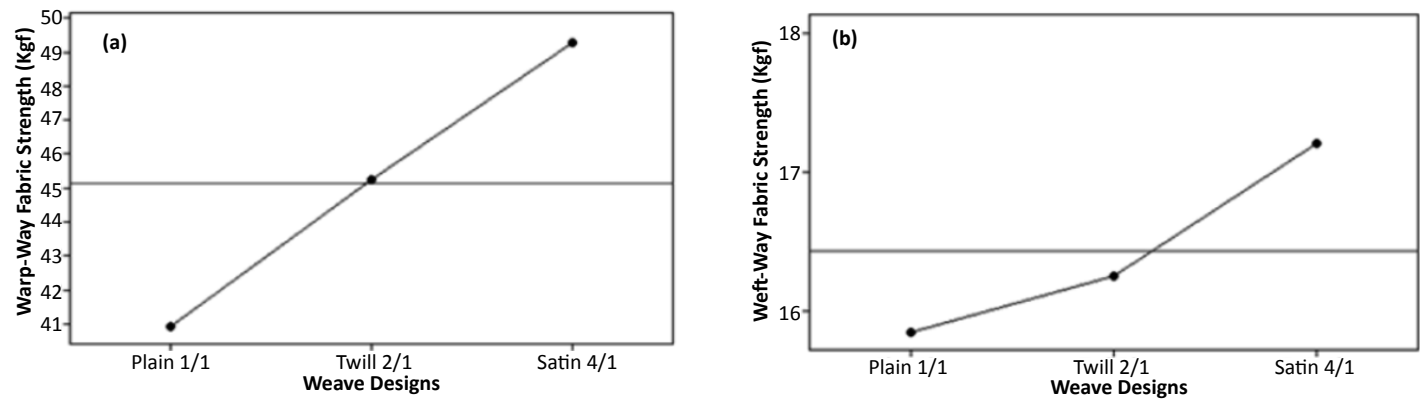

Figure 1: Effect of weave designs on fabric strength.
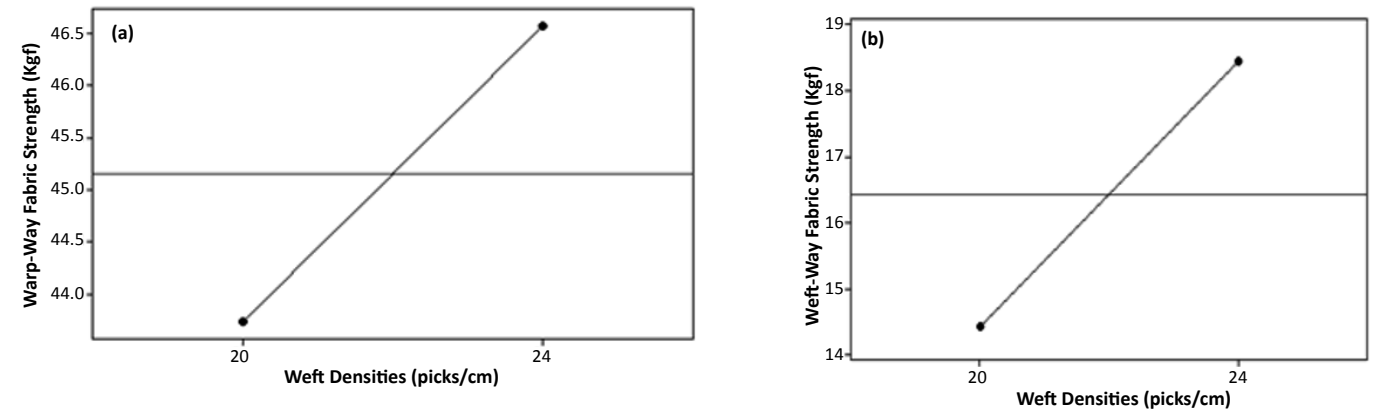

Figure 2: Effect of weft density on fabric strength.

\begin{tabular}{|c|c|c|c|c|c|c|c|c|c|c|c|c|}
\hline \multirow[t]{2}{*}{ Source } & \multicolumn{6}{|c|}{ Warp-wise } & \multicolumn{6}{|c|}{ Weft-wise } \\
\hline & DF & Seq SS & Adj SS & Adj MS & F-Value & P-Value & DF & Seq SS & Adj SS & Adj MS & F-Value & P-Value \\
\hline Weave Designs & 2 & 70.59 & 70.59 & 35.29 & 13.94 & .05 & 2 & 1.92 & 1.92 & 0.96 & 2.11 & .32 \\
\hline Weft Densities & 1 & 12.04 & 12.04 & 12.04 & 4.76 & .16 & 1 & 24.00 & 24.00 & 24.00 & 52.75 & .01 \\
\hline Error & 2 & 5.06 & 5.06 & 2.53 & & & 2 & 0.91 & 0.91 & 0.45 & & \\
\hline Total & 5 & 87.69 & & & & & 5 & 26.83 & & & & \\
\hline $\mathbf{S}$ & \multicolumn{6}{|c|}{1.59112} & \multicolumn{6}{|c|}{0.674537} \\
\hline R-Sq & \multicolumn{6}{|c|}{$94.23 \%$} & \multicolumn{6}{|c|}{$96.61 \%$} \\
\hline R-Sq (adj) & \multicolumn{6}{|c|}{$85.57 \%$} & \multicolumn{6}{|c|}{$91.52 \%$} \\
\hline
\end{tabular}

Table 3: Analysis of variance for fabric strength.

direction. Hussain et al. described that the fabric which had higher number of picks/cm showed the greater strength until the yarn failure occurred at the point where the crossing of yarn took place [13].

\section{Effect of fabric structural parameters on seam strength}

The failure of seam is the result of thread breakage and tearing of fabric, but the tearing of fabric is located near the seam; otherwise it will be wrong manipulation. In this investigation of data relevant to seam strength of $100 \%$ cotton woven fabric both in warp and weft direction influenced by three input factors such as weave designs (plain 1/1, twill $2 / 1$ and satin 4/1), weft densities (20 and 24 picks/cm) and sub-types of seam designs (SSa, SSb, SSc, LSa and LSb). The first two factors showed similar trend in the both directions of the seam that is (perpendicular and cross) but the third factor of seam designs behaved differently in case of warp and weft direction of seam by experimentally collected data. The behaviour of seam depended on all factors described above.

The seam strength value of six fabric increased by changing the construction parameters such as picks / cm (weft density) of fabric. These results of seam strength showed that there was direct influence of fabric properties and parameters on the final product after seeming. The seam designs which were chosen for this study showed the significant effect on seam strength.

The analytical results of data are given in Table 4 which showed the weave designs; weft densities and seam designs had significant effect on seam strength both in warp and weft direction. The analysis of variance showed that the effect of weave design was highly statistical significant in warp direction ( $\mathrm{p}$-value $=0.000)$ and weft direction ( $\mathrm{p}$-value $=0.002$ ); the effect of weft density was highly statistical significant in both directions ( $p$-value $=0.000$ ) and the effect of seam designs was statistical significant in warp ( $\mathrm{p}$-value $=0.000)$ and weft $(\mathrm{p}$-value $=0.004)$.

The main effect plot of seam strength data showed the similar trend as the fabric strength. It was concluded that the seam strength of satin weave fabric was highest than the other two fabric weaves as shown in Figure 3 . The loss of fabric strength due to the action of sewing by the impact of needle damage and ultimately the breaking of stitching line of fabric sewn was important representation. All these were establishing the relationship between strength of original and after seeming fabric.

Both in fabric warp and weft direction, the seam strength increased by increasing the weft density; shown in Figure 4, but the value of 

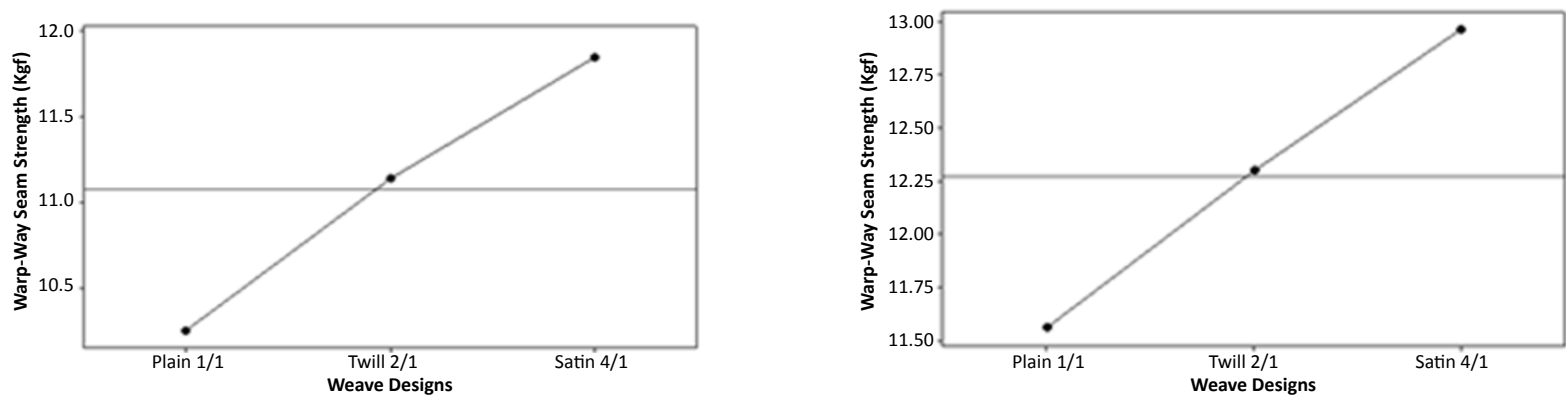

Figure 3: Effect of weave designs on seam strength.
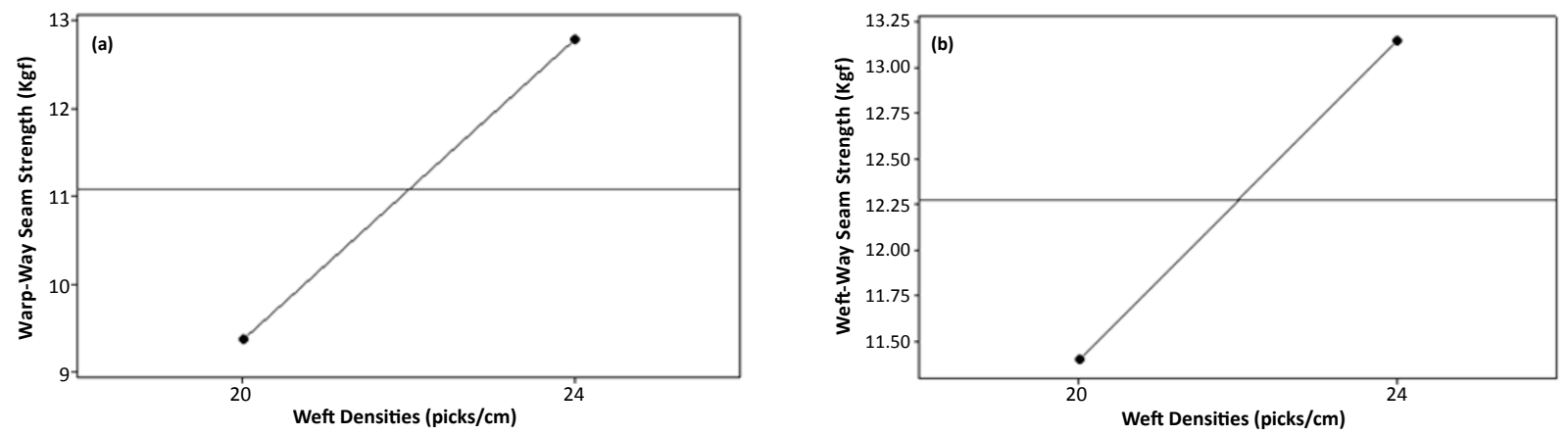

Figure 4: Effect of weft density on seam strength.

\begin{tabular}{|c|c|c|c|c|c|c|c|c|c|c|c|c|}
\hline \multirow[t]{2}{*}{ Source } & \multicolumn{6}{|c|}{ Warp-wise } & \multicolumn{6}{|c|}{ Weft-wise } \\
\hline & DF & Seq SS & Adj SS & Adj MS & F-Value & P-Value & DF & Seq SS & Adj SS & Adj MS & F-Value & P-Value \\
\hline Weave Designs & 2 & 12.85 & 12.85 & 6.42 & 11.49 & .000 & 2 & 9.81 & 9.81 & 4.90 & 8.35 & .002 \\
\hline Weft Densities & 1 & 87.38 & 87.38 & 87.38 & 156.23 & .000 & 1 & 22.88 & 22.88 & 22.88 & 38.93 & .000 \\
\hline Seam Designs & 4 & 29.70 & 29.70 & 7.42 & 13.28 & .000 & 4 & 12.55 & 12.55 & 3.13 & 5.34 & .004 \\
\hline Error & 22 & 12.30 & 12.30 & 0.55 & & & 22 & 12.93 & 12.93 & 0.58 & & \\
\hline Total & 29 & 142.2 & & & & & 29 & 58.17 & & & & \\
\hline $\mathbf{S}$ & \multicolumn{6}{|c|}{0.747866} & \multicolumn{6}{|c|}{0.766673} \\
\hline R-Sq & \multicolumn{6}{|c|}{$91.35 \%$} & \multicolumn{6}{|c|}{$77.77 \%$} \\
\hline R-Sq (adj) & \multicolumn{6}{|c|}{$88.60 \%$} & \multicolumn{6}{|c|}{$70.70 \%$} \\
\hline
\end{tabular}

Table 4: Analysis of variance for seam strength.

strength of the seam in fabric perpendicular direction were higher than weft. Seam performance and strength were affected by fabric characteristics, such as fabric designs, warp and weft density, size and weight of the thread used in sewing.

LSb seam design showed higher strength value in warp direction and SSc for weft, but in case of both directions, the lowest value of LSa seam design for all three weave designs; shown in Figure 5. The comparison of these seams with each other was not supportive because of two different classes of seams.

\section{Effect of fabric structural parameters on seam efficiency}

Efficiency of the seam is used to measure the durability of product. The optimization of efficiency value can be done by various factors such as seam designs, stitch density, sewing thread selection, needle and fabric material. The analysed results of data are given in Table 5 showed that seam designs had significant effect on seam efficiency. The weave designs had no significant effect on seam efficiency in warp direction because the $p$-value was greater than 0.05 but in weft direction weft density did not show significant effect on seam efficiency.
The data of seam efficiency is basically the mathematical application of fabric tensile strength and seam strength because the seam efficiency is defined as percentage value of seamed fabric to un-seamed fabric strength. The $4 / 1$ satin fabric gave the highest seam efficiency as compared to other two types of fabrics; see Figure 6. There was a significant positive correlation between the fabric and seam strength and the seam efficiency; higher fabric strength gave higher seam efficiency and vice versa.

Hui and Ng studied that fabric properties had significant effect on seam efficiency [18]. Gurarda described that there was some inevitable loss of fabric strength due to the action of sewing operation. The overall life of the product was also shortened by such a loss [19]. Seam efficiency increased both in warp and weft direction of the fabric by increasing weft density because of increased number of yarns under the seam; exposed in Figure 7.

The evaluation of seam efficiency of five different seam subtypes used in this study was shown in Figure 8. The LSb seam design showed the highest seam efficiency value in warp direction because 
Citation: Iftikhar F, Hussain T, Malik MH, Ali Z, Nazir A, et al. (2018) Fabric Structural Parameters Effect on Seam Efficiency-Effect of Woven Fabric Structural Parameters on Seam Efficiency. J Textile Sci Eng 8: 358. doi: 10.4172/2165-8064.1000358
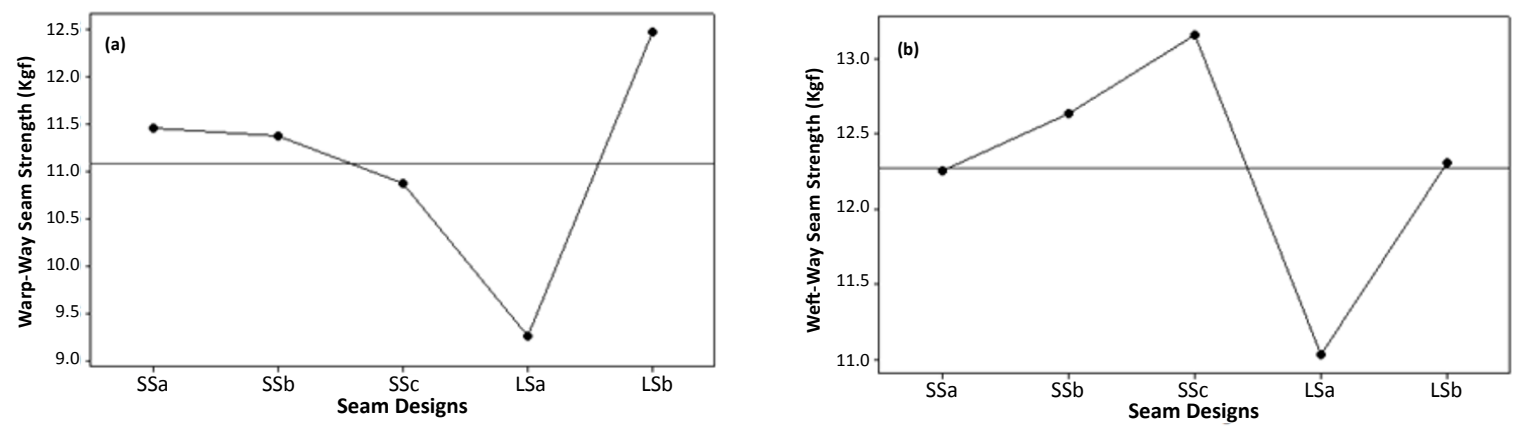

Figure 5: Effect of seam designs on seam strength.
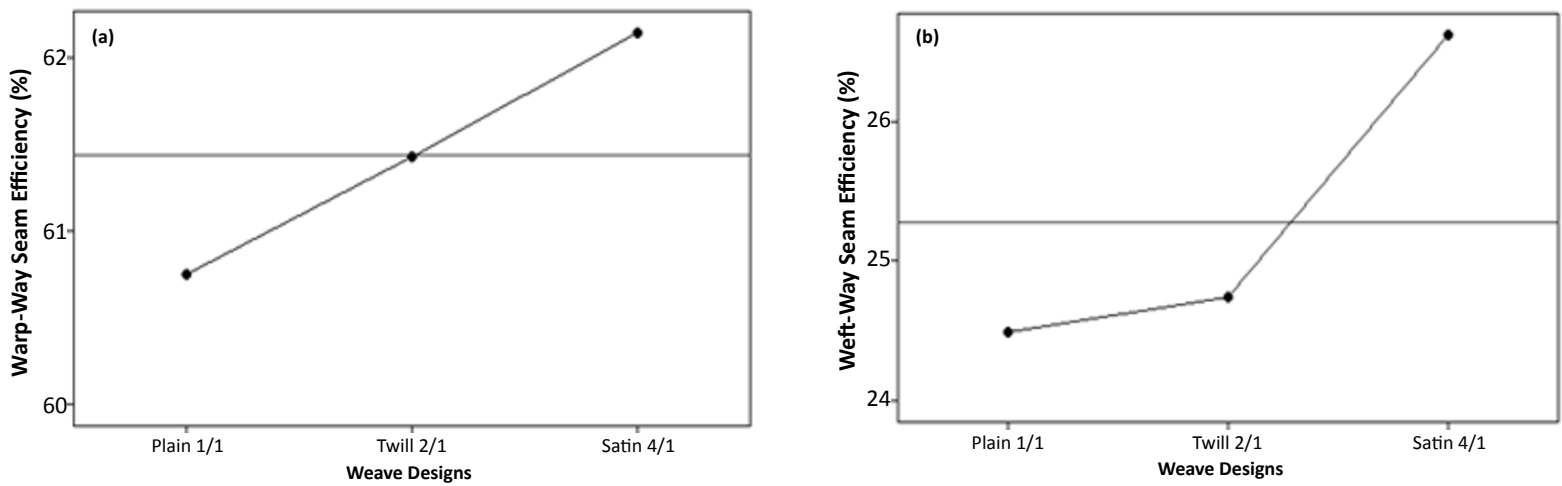

Figure 6: Effect of weave designs on seam efficiency.
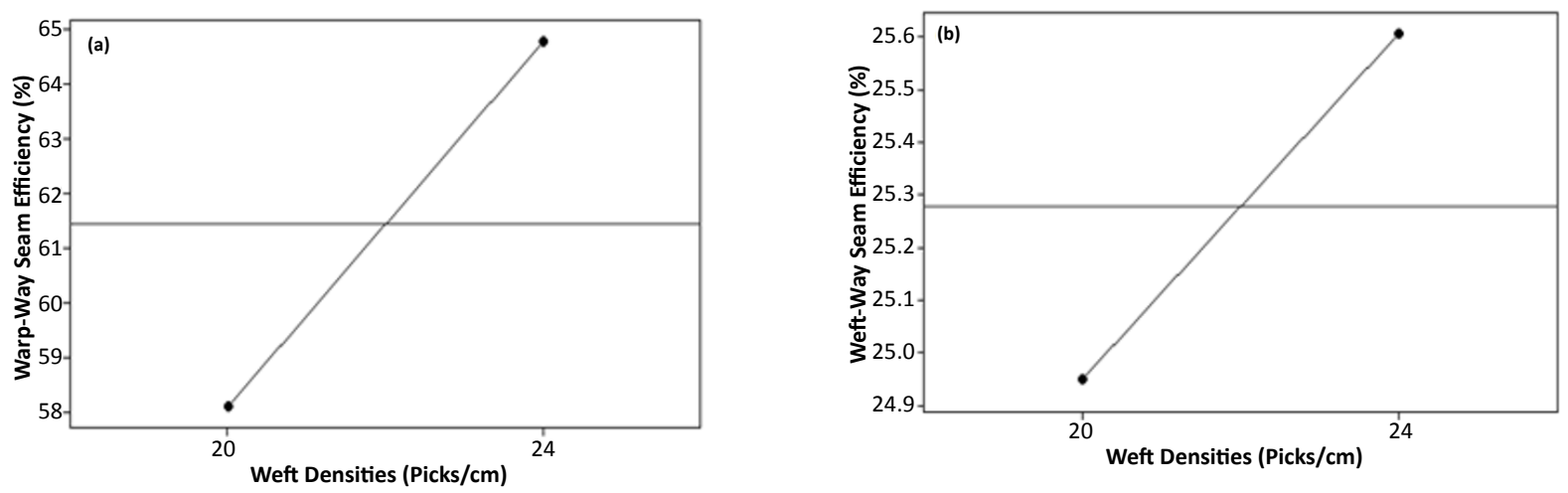

Figure 7: Effect of weft density on seam efficiency
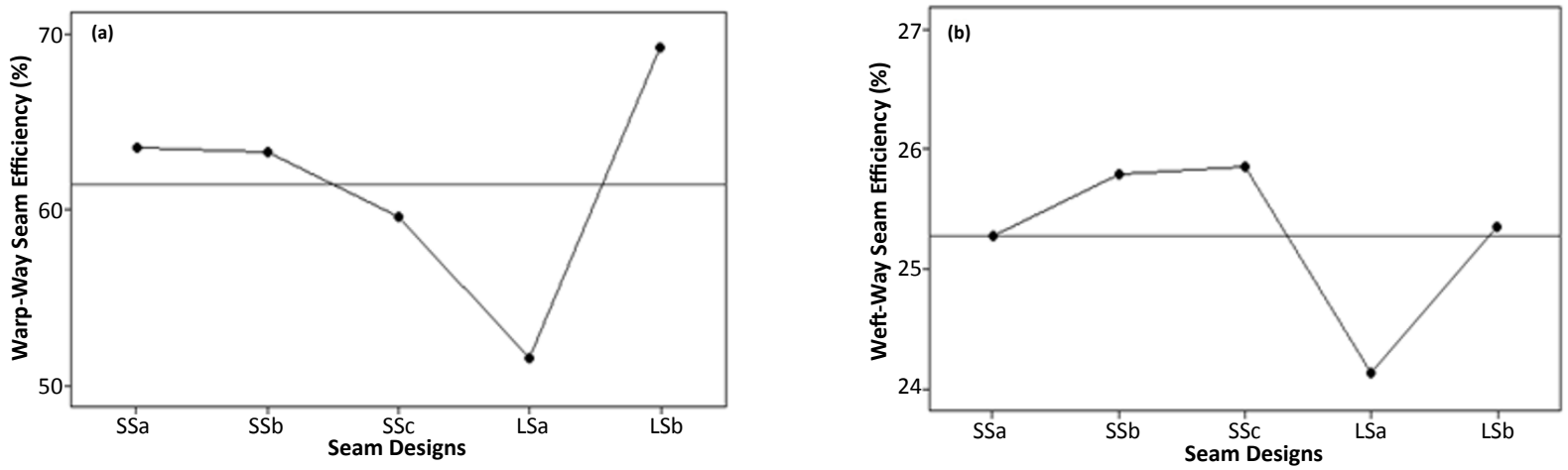

Figure 8: Effect of seam designs on seam efficiency. 


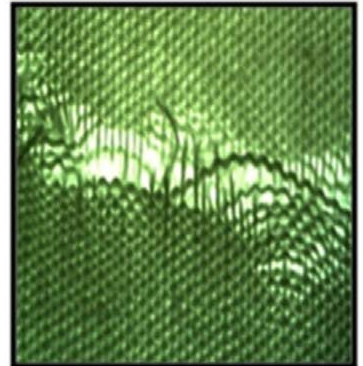

Bleached Plain (1/1) Weft

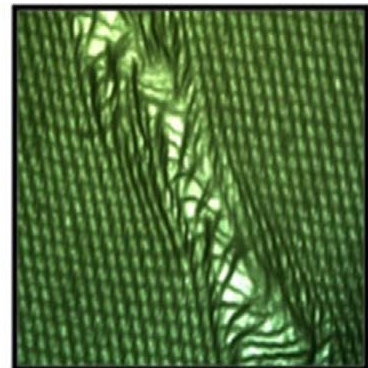

Bleached Twill (2/1) Weft

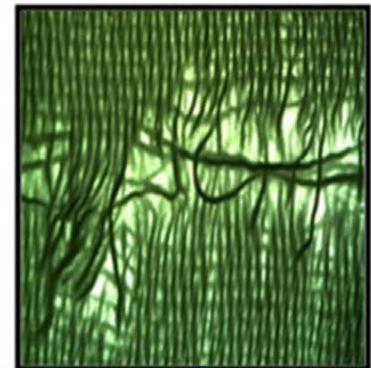

Bleached Satin (4/1) Weft

Figure 9: Scanned images of fabric breaking strength.

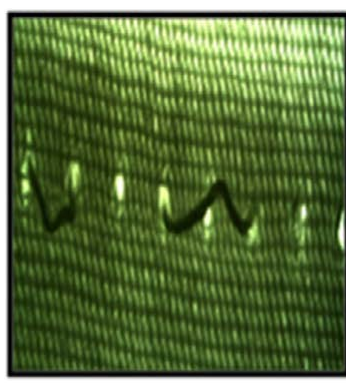

Bleached Plain (1/1) Weft

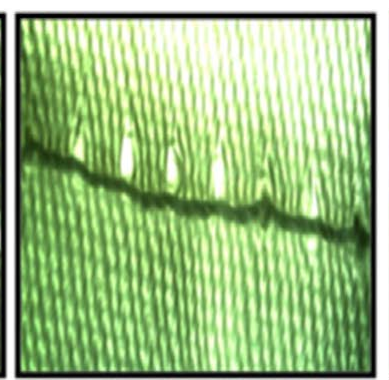

Bleached Twill (2/1) Weft

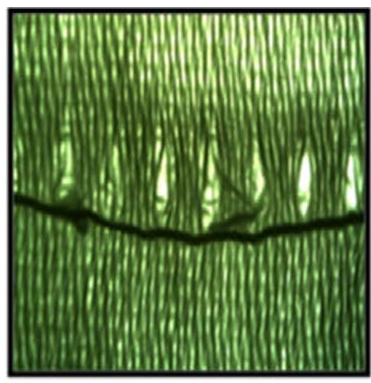

Bleached Satin $(4 / 1)$ Weft

Figure 10: Scanned images of seam breaking strength

\begin{tabular}{|c|c|c|c|c|c|c|c|c|c|c|c|c|}
\hline \multirow[t]{2}{*}{ Source } & \multicolumn{6}{|c|}{ Warp-wise } & \multicolumn{6}{|c|}{ Weft-wise } \\
\hline & DF & Seq SS & Adj SS & Adj MS & F-Value & P-Value & DF & Seq SS & Adj SS & Adj MS & F-Value & P-Value \\
\hline Weave Designs & 2 & 69.03 & 76.29 & 38.14 & 1.93 & .172 & 2 & 31.39 & 31.89 & 15.94 & 10.11 & .001 \\
\hline Weft Densities & 1 & 319.1 & 225.8 & 225.8 & 11.93 & .003 & 1 & 8.12 & 9.51 & 9.51 & 6.03 & .116 \\
\hline Seam Designs & 4 & 922.4 & 922.4 & 230.6 & 11.43 & .000 & 4 & 13.36 & 13.36 & 3.34 & 2.12 & .023 \\
\hline Error & 19 & 375.2 & 375.2 & 11.68 & & & 20 & 31.54 & 31.54 & 1.57 & & \\
\hline Total & 26 & 1685 & & & & & 27 & 84.43 & & & & \\
\hline $\mathbf{S}$ & \multicolumn{6}{|c|}{4.44426} & \multicolumn{6}{|c|}{1.25590} \\
\hline R-Sq & \multicolumn{6}{|c|}{$77.74 \%$} & \multicolumn{6}{|c|}{$76.56 \%$} \\
\hline R-Sq (adj) & \multicolumn{6}{|c|}{$69.54 \%$} & \multicolumn{6}{|c|}{$62.64 \%$} \\
\hline
\end{tabular}

Table 5: Analysis of variance for seam efficiency.

fabric weft yarn contributed in seam strength and seam was applied by overlapping three fabric plies. Whereas SSc gave the highest seam efficiency in the weft direction, because, fabric warp yarn contributed in seam strength and seam was applied by superimposition of four fabric plies as depicted in the seam construction image given in Table 2. LSa seam design gave the lowest efficiency in both warp and weft direction because of overlapping of low number of plies and no coverage of raw edges. The ultimate result showed that strength and thereby, the efficiency of seam was affected by constituent yarn of fabric in the seam direction, number of fabric plies and fabric characteristics (Figure 8) [20].

\section{Conclusion}

The data relevant to response variables such as fabric strength, seam strength and seam efficiency of $100 \%$ cotton woven fabric both in warp and weft direction influenced by fabric structural parameters of study. The scanned images of ruptured fabric and breaking seam showed that the strength and efficiency value for satin weave was more as compared to plain and twill weaves; presented in Figures 9 and 10.
The satin weave had the highest level of fabric strength and translation efficiency due to the low level of yarn interlacing and linearity and longer floats length. The low level of yarn integration in satin weave also allowed freedom of yarn mobility. The plain weave had a higher level of structural integrity due to crimp geometry produced by yarn interlacing. The higher crimp value increased the crimp angle which ultimately caused the jamming effect for the propagation of strength through the fabric, as a result fabric strength decreased.

The seam strength and efficiency of satin weave was higher as compared with plain and twill weaves due to the strength of basic fabric. The seam strength depended upon the strength of joining material because the sewing conditions decreased the strength value.

The strength and efficiency value of fabric and seam were increased by increasing the weft density of fabric. The increase number of picks enhanced the fiber volume fraction which raised the strength by reducing yarn inclination angle. By increasing weft density, inter-fiber friction and yarn to yarn interaction was also increased which opposed the fiber slippage. The direction of yarn in fabric and sewing thread had 
Citation: Iftikhar F, Hussain T, Malik MH, Ali Z, Nazir A, et al. (2018) Fabric Structural Parameters Effect on Seam Efficiency-Effect of Woven Fabric Structural Parameters on Seam Efficiency. J Textile Sci Eng 8: 358. doi: 10.4172/2165-8064.1000358

the same twist, so the yarn make nest together in case of twill weave and gave flatter surface in satin weave which made for propagation easy. Due to this effect the seam strength value of satin weave was higher than twill and plain weaves.

The seam designs had significant effect on seam strength and efficiency. It was found that LSa type seam gave the lowest seam efficiency among all the tested seams in both warp and weft direction.

\section{Future Research Suggestions}

Following studies may be under taken in future:

a) The same fabric structural parameters can be studied for knit fabric products to investigate the fabric strength, seam strength and seam efficiency.

b) The advance fiber material can be used by studying the same fabric structural and response parameters.

c) The Taguchi design of experiment can be applied for analysis of variance both for woven and knitted fabrics.

\section{Limitations}

This research emphasizes only on cotton fabric with selected fabric structural parameters and seam sub-types. The presented conclusion is effective only this group of parameters and cannot be used inclusively.

\section{References}

1. Behera BK, Chand S, Singh TG, Rathe P (1997) Sewability of denim. Int J Cloth Sci Tech 9: 128-140.

2. Shi H, Zhang L, Wang J (2017) Influence of seam types on seam quality of outdoor clothing. Int J Cloth Sci Tech 29: 553-565.

3. Yassen HA (2017) Study of the Relationship between sewing and fabric Parameters and Seam Strength. International Design Journal 7: 125-129.

4. Hui PCL, Chan KCC, Yeung KW, Ng FSF (2007) Application of artificial neural networks to the prediction of sewing performance of fabrics. Int $\mathrm{J}$ Cloth Sci Tech 19: 291-318.
5. Frydrych I, Greszta A (2016) Analysis of lockstitch seam strength and its efficiency. Int J Cloth Sci Tech 28: 480-491.

6. Laing RM, Webster J (1998) Stitches and seams, Manchester, England: Textile Institute.

7. Mukhopadhyay A, Ghosh S, Bhaumik S (2006) Tearing and tensile strength behaviour of military khaki fabrics from grey to finished process. Int J Cloth Sci Tech 18: 247-264.

8. Malek S, Jaouachi B, Khedher F, Said BS, Cheikhrouhou M (2017) Influence of some sewing parameters upon the sewing efficiency of denim fabrics. J Text I 5000: 1-13.

9. Glock RE, Kunz GL (1990) Apparel Manufacturing Sewn Product Analysis 4th edn. Prentice Hall.

10. Sular V, Mesegul C, Kefsiz H, Seki Y (2015) A comparative study on seam performance of cotton and polyester woven fabrics. J Text I 106: 19-30.

11. Germanova Krasteva D, Petrov H (2008) Investigation on the seam's quality by sewing of light fabrics. Int J Cloth Sci Tech 20: 57-64.

12. Nayak R, Padhye, Gon DP (2010) Sewing performance of stretch denim Journal of Textile and Apparel, Technology and Management 6: 1-9.

13. Hussain T, Tanwari A, Malik ZA (2010) Prediction of tensile strength of polyester / cotton blended woven fabrics. Indian J Fibre Text Res 35: 243-249.

14. ASTM D (2011) Standard Test Method for Breaking Strength and Elongation of Textile Fabrics. Annual Book of ASTM, pp: 5034-5095.

15. ASTM D (2007) Standard test method for failure in sewn seams of woven apparel fabrics. Annual Book of ASTM, pp: 1683-1707.

16. Banerjee PK (2010) Effect of sett and construction on Uni-axial tensile properties of woven fabrics. J Eng Fibers Fabr 5: 8-21.

17. Grosberg P (1969) The tensile properties of woven fabrics. Structural Mechanics of Fibers, Yarns, and Fabrics 1: 339-354.

18. Hui CL, Ng SF (2009) Predicting Seam Performance of Commercial Woven Fabrics Using Multiple Logarithm Regression and Artificial Neural Networks. Text Res J 79: 1649-1657.

19. Gurarda A (2008) Investigation of the Seam Performance of PET/Nylonelastane Woven Fabrics. Text Res J 78: 21-27.

20. Nazakat A, Abdul MR, Zamir A, Hafeezullah M, Ahmer H (2014) Effect of Different Types of Seam, Stitch Class and Stitch Density on Seam Performance. J App Em Sc 5: 32-43. 